\title{
Prescribing pattern and prescription cost minimization in type-II diabetes mellitus with therapeutic effectiveness of generic drugs in a multi-super specialty hospital.
}

\author{
Arun Kumar S*, Subba Rao Ch, Priyanka D \\ Department of Pharmacy Practice,Vaageswari College of Pharmacy, Karimnagar, JNTUH, India.
}

\begin{abstract}
Pharmacoeconomics is a branch of health economics related to the most economical and efficient use of pharmaceuticals. Pharmaco economic research identifies measures and compares the costs and outcomes of pharmaceutical products and services. To prove that use of generic drugs can minimize the prescription cost of Type-II Diabetic patients with or without co-morbidities. To reduce burden on the consumers for effective management of healthcare system and to make more effective use of limited resources for minimization of healthcare benefits at lower cost.
\end{abstract}

Scope of work: The present work focuses on improving the use of generic drugs and minimizing the prescription cost of Type II Diabetes patients with or without co-morbidities.

- Industry: It helps in deciding among specific research and development alternatives

- Government: It helps in determining programme benefits and prices paid

Private sector: It helps in designing insurance benefit coverage.

Keywords: Pharmaco economics, Generic drugs, Co-morbid conditions, Health care benefits

\section{Introduction}

\section{Pharmacoeconomics}

Pharmaco economics is a branch of health economics related to the most economical and efficient use of pharmaceuticals. Pharmaco economic research identifies measures and compares the costs and outcomes of pharmaceutical products and services [1-4].

Pharmaco economics evaluation: Pharmaco economic evaluation involves measurement of inputs (costs) and outcomes (benefits).

Cost can be measured in following ways:

- Cost/unit

- Cost/treatment

- Cost/person

- Cost/person/year

- $\mathrm{Cost} /$ case prevented

- Cost/life saves

- Cost/DAILY (Disability-Adjusted Life Year).

Outcomes (Benefits): In assessing outcomes it is important to take both positive and negative outcomes. Positive outcome is a measure of drugs efficacy. Negative outcomes include side effects, treatment failure and development of drug resistance [5-7].

\section{Pharmaco-economic Evaluation}

There are 2 categories in Pharmaco economic evaluation, they are:
Economic evaluation:

- $\quad$ Costs benefit analysis (CBA)

- $\quad$ Cost effective analysis (CEA)

- Cost minimization analysis (CMA)

- Cost utility analysis (CUA)

Humanistic evaluation:

- Quality of life

- Patient preferences

- Patient satisfaction.

\section{Economic evaluation}

Costs benefit analysis: This is the most difficult of all evaluation techniques. It is a basic tool for identification, measurement and comparison of benefits and costs of program or treatment alternatives [8,9]. In this analysis costs and benefits are easily compared, when benefits are assigned a monetary value. This analysis may ignore intangible benefits (pain, anxiety, stress), because these are difficult to express in monetary terms [10-12].

Cost effective analysis: It is a tool used to make decisions about which medical care should be offered and helps in health improvement i.e. cost effective analysis helps in choosing the drugs which have equivalent or better effect at low cost, thus reducing the burden on common man [13-15].

Cost utilization analysis: It can be defined as the ratio between the cost of health related issues and the benefit obtained from the expenses invested (measured in quality of life i.e. based on number of year lived with good health by the patient). 
Citation: Arun Kumar S, Subba Rao Ch, Priyanka D. Prescribing pattern and prescription cost minimization in type-II diabetes mellitus with therapeutic effectiveness of generic drugs in a multi-super specialty hospital. Adv Cell Sci Tissue Cult. 2018;2(1):16-20

Cost minimization analysis: When two or more interventions are evaluated and assumed to be equivalent in terms of a given outcome consequence. Cost associated with each intervention may be evaluated and compared. In this analysis outcome of dugs proven to be equal, although the acquisition and administration costs may be significantly different. It is an important Pharmaco economic evaluation tool. This method is used to compare the costs of different interventions that have been proven to equivalent in therapeutic efficacy. The limitations of this cost evaluation method are that it can only be used to compare treatments that have to provide the same benefits or effectiveness. In this way it helps the decision makers can choose the best treatment with lowest cost.

\section{Factors which aid in cost minimization analysis}

- $\quad$ Limited knowledge on cost variations

- $\quad$ Limited studies

- $\quad$ Limited awareness of common people on cost of drugs

- Increased expenditure at all budget levels starting from individual to national

- Cost burden on patients leading to less adherence to medication

- Financial burden on the family

- Lowering of rupee value due to increased expenditure of the individual citizen

- An average $20-60 \%$ of total expenses of a family are on medicines

- Unavailability to middle and lower class people due to higher cost

- No national health service is available to all the citizens hence the payment is from individual pockets in majority of population

- Less utilization of generics even though there is availability

- A misconception of people that costly drugs provide more efficacy than less cost.

\section{Values found in pharmaco economics}

- $\quad$ Fixing the prices of a new drug and re-fixing the price of an existing drug

- $\quad$ Finalizing a drug formulary

- Creating data for promotional materials of medicines

- Compliance of requirements for drug license

- Including a drug in the medical or insurance reimbursement

- Introducing of new schemes and programs in hospital and clinical pharmacy

- Drug development and clinical trials (Table 1).

\section{Diabetes}

Type II Diabetes Mellitus refers to resistance to insulin action, inadequate insulin secretion or inappropriate glucagon secretion. Its signs and symptoms include polyuria, polydipsia,
Table 1. Pharmacoeconomics evaluation.

\begin{tabular}{|c|c|c|}
\hline S.No. & Category & Costs \\
\hline \multirow{5}{*}{1} & \multirow{5}{*}{ Direct medical costs } & Medication \\
\hline & & Supplies \\
\hline & & Lab tests \\
\hline & & Health care professional times \\
\hline & & Hospitalization \\
\hline \multirow{4}{*}{2} & \multirow{4}{*}{ Direct non-medical costs } & Transportation \\
\hline & & Food \\
\hline & & Family care \\
\hline & & Home aids \\
\hline \multirow[b]{2}{*}{3} & \multirow[b]{2}{*}{ Indirect costs } & Lost wages (mobidity) \\
\hline & & $\begin{array}{c}\text { Income forgone because of premature } \\
\text { death }\end{array}$ \\
\hline \multirow{4}{*}{4} & \multirow{4}{*}{ Intangible costs } & Pain \\
\hline & & Suffering \\
\hline & & Inconvenience \\
\hline & & Grief \\
\hline \multirow{2}{*}{5} & \multirow{2}{*}{ Opportunity costs } & Lost opportunity \\
\hline & & Revenue forgone \\
\hline
\end{tabular}

polyphagia, weight loss, blurred vision, lower extremities paresthesis and yeast infection [16,17]. Blood glucose increase of over $20 \mathrm{mg} / \mathrm{dl}$ occurring at the end of the night is called as dawn phenomenon $[18,19]$.

\section{Goals}

- To eliminate symptoms and to prevent or slow the development of complications

- $\quad$ Normalize blood pressure and blood glucose levels

- Control of lipids

- Smoking cessation

- Appropriate goal setting

- Dietary and exercise modifications

- Medications

- Self monitoring of blood glucose

- Monitoring for complications like nephropathy, retinopathy and neuropathy

- Laboratory assessment

- Diet and exercise

- Treatment with sulfonylureas or insulin do not increase the risk of macrovascular disease

- Metformin reduces macrovascular risk in patients who are obese

- In Chronic kidney disease, iron and erythropoeitintreatment causes a significant increase in HbAlc without affecting blood glucose levels.

\section{Prevention of type II diabetes mellitus}

- Weight reduction

- Proper nutrition

- Regular physical activity 
- Cardiovascular risk factor reduction

- Cessation of smoking

- Hypertension and dyslipidemic treatment

- Low sodium high potassium diet to decrease blood pressure.

\section{Pharmacologic treatment}

- $\quad$ Biguanides - metformin, phenormin

- Sulfonylureas - glyburide, glipizide, glimipride

- Metaglitinide derivatives - repaglinide, nateglinide

- Alpha glucosidase inhibitors - acarbose

- Thiazolidinediones - pioglitazone, rosiglitazone

- Glucagon like peptide 1 agonists - exenatide, albiglutide

- Dipeptidyl peptidase IV inhibitor - sitagliptin, saxagliptin, linagliptin

- Selective sodium glucose transporter 2 inhibitors empagliflozin, canagliflozin, dapagliflozin

- Insulins

- Amylin omimetics - dramlintide acetate

- Bileacid sequestrants - colesevelam

- Dopamine agonists - bromocriptine mesylate.

\section{Biguanides}

Metformin is first line therapy for Type II Diabetes Mellitus and it is proved to be safe and effective. It works by decreasing hepatic gluconeogenesis production also decreases intestinal absorption of glucose and improves insulin sensitivity by increasing peripheral glucose reuptake and utilisation. Rarely causes hypoglycaemia compared to sulfonyl ureas. It is contraindicated in patients with renal function [20,21].

\section{Sulfonyl ureas}

- Glyburide a second generation sulfonyl urea, is the more potent and exhibits fewer drug interactions than first generation agents. They have longer half-life

Dose: $1.25 \mathrm{mg}, 2.5 \mathrm{mg}, 5 \mathrm{mg}$.

- Glipizide is also a more potent drug with few drug interactions.

Dose: $5 \mathrm{mg}, 10 \mathrm{mg}, 2.5 \mathrm{mg}$.

- Glimepiride stimulates insulin secretion from beta cells which decreases the rate of hepatic glucose production and increase insulin receptor sensitivity.

Dose: $1 \mathrm{mg}, 2 \mathrm{mg}, 4 \mathrm{mg}$.

\section{Metaglitinide derivatives}

- Repaglinide administration is preferable in patients with increased risk for hypoglycaemia who still need insulin secretagogone stimulates insulin secretion and it is the better control of PPBS.

Dose: $0.5 \mathrm{mg}, 1 \mathrm{mg}, 2 \mathrm{mg}$
- Nateglinide mimics endogenous insulin patterns which restores insulin secretion and controls molten glucose sugars.

Dose: $60 \mathrm{mg}, 120 \mathrm{mg}$.

\section{Alpha glucosidase inhibitors}

- Acarbose is absorbed to very small extent and thus have rare liver abnormalities detected

- $\quad$ Dose: $25 \mathrm{mg}, 50 \mathrm{mg}, 100 \mathrm{mg}$

- Miglitol is not absorbed and no liver function abnormality is detected.

- Dose: $25 \mathrm{mg}, 50 \mathrm{mg}, 100 \mathrm{mg}$.

\section{Thiazolidine diones}

- Pioglitazone increases target cell response without increasing insulin secretion from pancreas.

Dose: $15 \mathrm{mg}, 30 \mathrm{mg}, 45 \mathrm{mg}$

- Rosiglitazone is an insulin sensitizer and it increases glucose uptake of skeletal muscle and adipose tissue. It lowers plasma insulin levels with Type II Diabetes Mellitus with insulin resistance.

\section{Glucagon like peptide 1 agonists}

- Exenatide enhances glucose dependent insulin secretion which suppresses inappropriately elevated glucagon secretion and slows gastric emptying.

Dose: $250 \mathrm{mcg} / \mathrm{ml}$ (1.2 ml, $2.4 \mathrm{ml}$ vial).

- $\quad$ Liraglutide stimulates $\mathrm{G}$ protein in pancreatic beta cells and it is contraindicated in patients with previous or family history of medullary thyroid carcinoma or multiple endocrine neoplasia syndromes Type2.

Dose: $18 \mathrm{mg} / 3 \mathrm{ml}$.

- Albiglutide is given once weekly.

- Dulaglutide is an incretin mimetic that decreases gastric emptying and decreases the glucagon secretion and it is given once weekly

Dose: $0.7 \mathrm{mg} / 0.5 \mathrm{ml} 1.5 \mathrm{mg} / 0.5 \mathrm{ml}$.

- Lixisenatide is a SC solutions prefilled pen.

\section{Dipeptidyl peptidase IV inhibitor}

- $\quad$ Sitagliptin OD, $25 \mathrm{mg}, 50 \mathrm{mg}, 100 \mathrm{mg}$.

- Saxagliptin stimulates insulin release to increased glucose levels.

Dose: $2.5 \mathrm{mg}, 5 \mathrm{mg}$ OD

- Linagliptin prolongs incretin hormone activity.

Dose: $5 \mathrm{mg}$ OD

- Alogliptin reduces fasting and PPBS.

Dose: $6.25 \mathrm{mg}, 12.5 \mathrm{mg}, 25 \mathrm{mg}$ OD.

Selective sodium glucose transporter 2 inhibitors

These lower renal glucose threshold: 
Citation: Arun Kumar S, Subba Rao Ch, Priyanka D. Prescribing pattern and prescription cost minimization in type-II diabetes mellitus with therapeutic effectiveness of generic drugs in a multi-super specialty hospital. Adv Cell Sci Tissue Cult. 2018;2(1):16-20

- Canaglifozin increases glucose excretion.

Dose: $100 \mathrm{mg}, 300 \mathrm{mg}$

- Dapagliflozin reduces glucose reabsorption in kidney hence increase glucose excretion. Dose: $5 \mathrm{mg}, 10 \mathrm{mg}$

- Empagliflozin

Dose: $10 \mathrm{mg}, 25 \mathrm{mg}$

\section{Bile acid sequestrants}

- Colesevelam

Dose: $625 \mathrm{mg}$

\section{Rapid acting insulins}

- Insulin aspart, Onset of action: 5-15 min, Duration of action: $3-5$ hrs, Peak effect: $30-90$ mins

Dose: 100 units per $\mathrm{ml}$ and also insulin pumps

- Insulin glusine

Dose: 100 units/ml

- Insulin lispro duration of action $4 \mathrm{hrs}$

Dose: 100 units/ml

- Insulin inhaled it is orally inhaled

Dose: 4 units /cartridge, 8 units/cartridge, 12 units/cartridge.

\section{Short acting insulins}

These have slower onset of action

- Regular insulin Onset of action: 0.5-1 hr, Duration of action: 4-6 hrs, Peak effects: 2-4 hrs.

\section{Intermediate acting insulins}

These have slow onset of action and longer duration of action

- Insulin nph Onset of action: 3-4 hrs, Peak effects: 8-14 hrs, Duration of action: 16-24 hrs.

\section{Long acting insulins}

These have longer duration of action:

- Insulin detemir Duration of action: $24 \mathrm{hrs}$.

Dose: 100 units $/ \mathrm{ml}$

- Insulin glargine constant release

Dose: 100 units/ml

- Insulin degludec is an ultra-long acting which has duration of action greater than $42 \mathrm{hrs}$ and half-life of $25 \mathrm{hrs}$.

Dose: 100 units/ml, 200 units/ml.

\section{Dopamine agonists}

- Bromocriptine Dose: $0.8 \mathrm{mg}, 2.5 \mathrm{mg}$ tablet.

- It acts centrally and do not cause hypoglycemia and weight loss. It decreases the frequency of cardiovascular events and resets abnormally elevated hypothalamic drive for increased plasma glucose, triglycerides and free fatty acid levels in fasting and postprandial states in patients with insulin resistance.

\section{Methodology}

This study is a prospective observational study which was conducted over a period of 6 months among Type II Diabetes Mellitus patients at Karimnagar district, Telangana. This study took place between August to January 2017.

\section{Study population}

During the study period, the patient's data was collected considering the following inclusion and exclusion criteria.

\section{Inclusion criteria}

- $\quad$ Type II Diabetes patients with or without comorbidity of both genders using oral hypoglycaemic agents

- Patients of age greater than 18 years

\section{Exclusion criteria}

- Patients using Insulin as their regular medication

- Gestational diabetic patients

Subjects are selected and their relevant information like demographic details, medical and medication status were collected from the patient's prescription, case sheet and patient/ patient representative in the data collection form. Then the cost of each prescription is calculated of both inpatients and out patients. Then the patients were categorised in to two categories like

- Inpatients

- Outpatients.

These two categories are further divided according to their medical condition like:

- $\quad$ Patients with Type II Diabetes Mellitus

- Patients with Type II Diabetes Mellitus with diabetic complications

- Patients with Type II Diabetes Mellitus with other comorbidities

- $\quad$ Patients with Type II Diabetes Mellitus with infections and miscellaneous complaints.

Then the minimum available cost of each drug (generics) in the market in individual prescriptions was substituted in place of original prescription. The cost variation was compared between the minimum costs of drug available with the original prescription which contains branded or branded generics. The average prescription cost of each patient was calculated and finally the average price variations are reported when generics are substituted in place of branded or branded generic medicines. The prices for brand and branded generics were obtained using the help of pharmacies and soft wares $(1 \mathrm{mg})$. The prices of generic versions are obtained from the official price list of generic medicines by the department of pharmaceutical, Government of India.

\section{Discussion}

- Accounting the economic condition of the patient and making it an intervention. 
- Helping in improved medication adherence by minimizing the cost.

- Helping in reducing the cost burden on government health schemes include national schemes like Rashtiya Swasthiya Bima Yojana (RSBY) - for below poverty line family, Employment State Insurance Scheme (ESIS), Central Government Health Scheme (CGHS)- for central govt. employees and pensioners and their dependents, Aam Aadmi Bima Yojana (AABY) - for rural landless hould hold, Janashree Bima Yojana and state schemes like Aarogyasri, Employees health scheme etc by educating the government about the cost burden when compared to brand with generic.

- Identify less costly alternative.

- Helps in improving monetary values in developing countries such as India.

- Prescribing of medicines based on patient economic status.

\section{Conclusion}

This study shows to increase a prevalence of disorder, through creating awareness about the Type-II Diabetic Drugs and prescription cost minimization by using Non-branded Drugs. The Developing countries like India, mostly middle class people cannot offered too much cost on drugs especially Chronic disorder like Type-II Diabetes Patients. Instead of purchasing branded drugs better to prefer Non-branded drugs, this can reduce cost burden.

\section{References}

1. Jainam VS. Pharmaco economic evaluation cost minimization analysis of anti-diabetic therapy in Gujarat. International Journal of Medical Research \& Health Sciences. 2016;3:34-43.

2. Scaria S. Pharmaco economics: Principles Methods and Indian scenario. Int J Pharm Sci Rev Res. 2015;37-46.

3. Suleiman JA. Pharmaco economic evaluation of antidiabetic therapy in a Nigerian tertiary health institution. Annals of African Medicine. 2006;5:132-7.

4. Powar PV. Pharmaco-economics-Costs of drug therapy to healthcare systems. Journal of Modern Drug Discovery and Drug Delivery Research. 2014;1:1-6.

5. Carter JT, Ebel JA. A comparison of Pharmaco-economics topics in journals and entry-level pharmacy degree curricula. American Journal of Pharmaceutical Education. 2001;65:30-34.

6. Gattani SG. Pharmaco-economics: A review. Asian Journal of Pharmaceutical and Clinical Research. 2009;2:15-26.

7. Dong H. Cost-minimization analysis of metformin and acarbose in treatment of type 2 diabetes. Value in health regional issues. 2015;84-8.

8. Nathwani D. Cost-minimization analysis and audit of antibiotic management of bone and joint infections with ambulatory teicoplanin in-patient care or outpatient oral linezolid therapy. Journal of Antimicrobial Chemotherapy. 2003;51:391-6.

9. Heaney DC. Cost minimization analysis of antiepileptic drugs in newly diagnosed epilepsy in 12 European countries. Epilepsia. 2000;41:37-44.

10. Cheng JW. Pharmaco-economic analysis of clopidogrel in secondary prevention of coronary artery disease. Journal of Managed Care Pharmacy. 2007;13:326-36.

11. Alrasheedy AA. The experiences of implementing generic medicine policy in eight countries: A review and recommendations for a successful promotion of generic medicine use. Saudi Pharmaceutical Journal. 2014;491503.

12. Chen GJ. A cost-minimization analysis of diuretic-based anti-hypertensive therapy reducing cardio vascular events in older adults with isolated systolic hypertension cost effectiveness and resource allocation. 2005.

13. Fitch K. Medical Claim Cost Impact of Improved Diabetes Control for Medicare and Commercially Insured Patients with Type 2 Diabetes. Journal of Managed Care Pharmacy. 2013;19:609-20.

14. Meresz. Cost-minimisation analysis of basal insulin analogues for treatment of type 2 diabetes. Lege Artis Medicinae. 2012;22:669-76.

15. Abate N, Chandalia M. Ethnicity and type-2 diabetes-focus on Asian Indians. Journal of Diabetes and its Complications. 2001;15:320-27.

16. American Diabetes Association. Treatment of hypertension in adults with diabetes. Diabetes Care. 2002;25:71-3.

17. American Diabetes Association. Economic coast of diabetes in the US in diabetic care. 2017;26:917-32.

18. American Diabetes Association. Standards of Medical Care in Diabetes Care. 2007;30:4-41.

19. American Diabetes Association. Standards of Medical Care in Diabetes Care. 2013;36:1-66.

20. Diabetes Management in General Practice Guidelines for Type 2 Diabetes. 2012.

21. Diagnosis and classification of diabetes mellitus. American Diabetes Association Diabetes Care. 2012;35:67.

\section{*Correspondence to:}

Arun KS

Department of Pharmacy Practice

Vaageswari College of Pharmacy, JNTUH

Karimnagar

India

Tel: 09502588612

E-mail: chamakurii.subbu@gmail.com 